\title{
The numerical analysis of the flow and separation efficiency of a two-phase horizontal oil-gas separator with an inlet diverter and perforated plates
}

\author{
A. Efendioglu ${ }^{1}$, J. Mendez ${ }^{2}$ \& H. Turkoglu ${ }^{1}$ \\ ${ }^{1}$ Department of Mechanical Engineering, Gazi University, Turkey \\ ${ }^{2}$ Faculty of Engineering, Energy Department, \\ Universidad del Zulia, Venezuela
}

\begin{abstract}
Two-phase horizontal gravity separators are widely used in the petroleum industry. Design of these separators are based on empirical correlations and the design approach is described by the international standard API12J (American Petroleum Institute). Other literature provides different design approaches for defining the length and diameter of separator. However, there is no clear described method to determine the position of diverter neither in literature nor in API standards.

In this study, the main sizes of a separator were determined for a specific oilgas mixture using the empirical correlations from API and literature. To analyze the effects of the position of the diverter and perforated plates on the separation efficiency; two-phase flow simulations were conducted using CFD software ANSYS CFX. The CFD simulations were carried out for two different diverter plate distances from the inlet. The diverter plate was located $100 \mathrm{~mm}$ and $170 \mathrm{~mm}$ from the inlet. Additionally, simulation was also performed with perforated baffle plates when the diverter plate is positioned $170 \mathrm{~mm}$ from the inlet. To estimate the effects of these different configurations on separation efficiency, the CFD simulations results were compared.

It has been observed that perforated plates and position of the inlet diverter affect the separation efficiency. When the inlet diverter is located $100 \mathrm{~mm}$ from the inlet, the separation efficiency of $98.5 \%$ is obtained. When the inlet diverter is located at a distance $170 \mathrm{~mm}$ from the inlet, the separation efficiency increases
\end{abstract}


to $99.32 \%$. When perforated plates are assembled onto the separator, the separation efficiency increases further. A petroleum company, which produces about 25,550,000 barrels of oil per year, can save 252,945 barrels of oil every year if the separation efficiency increases by $0.99 \%$. This provides $\$ 27,823,950$ extra profit per year.

Keywords: oil-gas separator, two phase flow, CFD, API 12J.

\section{Introduction}

From petroleum wells oil and gas are obtained as mixture of different compounds like oil, gas, water and solid particles. Hence, the first process applied to this mixture is the separation of gas and oil. Gravity separators have common usage for separating oil, gas and liquid in petroleum and natural gas production fields. Gravity separators are designed in horizontal, vertical and spherical configurations, depending on the specific necessity of the well field. The horizontal gravity separators have low manufacturing cost and have wide interphase area in order to enhance the separation [1]. Hence, the horizontal separators are widely used for separation of gas and oil mixtures with high gasoil ratio. Schematic view of a typical horizontal gravity separator is shown in fig. 1. As seen in this figure, mixture entering the separator impinges on the diverter plate located at a small distance from the inlet. As a result of the impingement, the mixture loses its momentum and due to the gravitational effect majority of the oil droplets settles down as gas and some oil droplets continue flowing together. Consequently, the diverter plate plays an important role on the separation process. The separation process is also affected by droplet size, retention time, the difference between densities of oil-gas and flow regime. The separation efficiency increases with increasing retention time. Density difference between two phases is also important for efficiency of separators. When the density difference increases, separation efficiency increases. Furthermore, flow regime is also important for the efficiency of separators. Slugging is not desired. Lastly, so as to increase the efficiency of the separator, the interphase area should be wide [2].

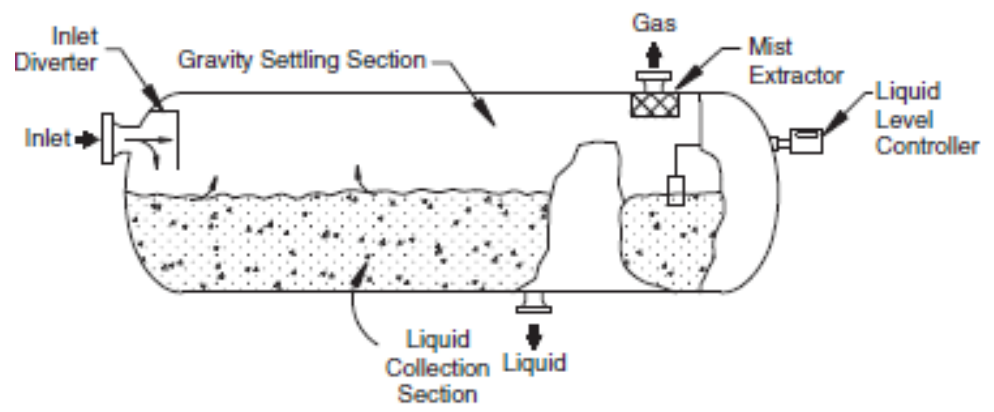

Figure 1: $\quad$ Schematic view of a typical horizontal gravity separator [2]. 
In the literature there are a limited number of studies addressing the effects of above parameters on the separation efficiency. Abdulkadir et al. [3] analyzed the effect of inlet mixture speed and droplet size on separation efficiency in their experimental work. It was seen that inlet velocity and droplet size has a significant effect on separation efficiency. Méndez [4] numerically analyzed the vertical oil-gas separators using a software package.

Design of horizontal gravity separators are based on empirical correlations and the design approach is described by the international standards such as API12J (American Petroleum Institute). Other literature provides different design approaches for determining the length and diameter of separators. Furthermore, there is not enough study about the effects of the location of the diverter plate and the perforated plates on the separation efficiency and flow field in the separator.

\section{Oil-gas separator design}

In this study, the size of a separator was determined for the oil-gas mixture properties of which are given in Table 1 using the empirical correlations from API 12J and literature [2]. The diameter and the length of the separator were found as 36 inch and $10 \mathrm{ft}$, respectively. According to API 14E the inlet and outlet diameters were both determined as 14 inch.

Table 1: $\quad$ Oil-gas sample properties.

\begin{tabular}{|l|c|}
\hline Gas flow rate & $23.8 \mathrm{MMscfd}$ at 0.6 specific gravity \\
\hline Oil flow rate & $2000 \mathrm{BOPD}$ at $40 \mathrm{API}$ \\
\hline Operating pressure & $1000 \mathrm{psia}$ \\
\hline Operating temperature & $60^{\circ} \mathrm{F}$ \\
\hline Droplet size & $140 \mu \mathrm{m}$ \\
\hline Retention time & $3 \mathrm{~min}$ \\
\hline
\end{tabular}

\section{Modelling of two phase flow and mathematical formulation}

Flow in oil-gas separators behave as a multiphase flow. The gas and liquid phases have different velocities and properties in the same flow domain. Phases exchange momentum, heat and mass through interface between two phases which move and change the shape continuously. Although the residence time within the separator is appreciable, the phenomena of separation is considered fast. As a result the energy exchange due to possible difference of temperatures is negligible. To mathematically model two phase flows, different methods are used. Proper model for a given two-phase flow depends on the flow structure [6]. In the present study, considering the volume fraction of the dispersed phase, Méndez [4], the oil droplets as a dispersed phase and the gas as the continuous phase, the flow is modeled using Eulerian-Lagrangian method. In this model, motion of continuous phase (gas phase) is governed by continuity and 
momentum equations from an Eulerian framework. Motion of the dispersed phase (oil droplets) is governed by the Newton' equation of motion. Momentum exchange between the phases (oil droplet and gas) represented by a source term in the momentum equation of the continuous phase.

Assuming flow is incompressible, in Cartesian coordinate system, the governing equations for the gas (continuous phase) can be written as below:

\section{Conservation of mass}

$$
\frac{\partial \rho}{\partial t}+\frac{\partial \rho}{\partial x}(\rho u)+\frac{\partial \rho}{\partial y}(\rho v)+\frac{\partial \rho}{\partial z}(\rho w)=0
$$

Momentum equations

$$
\begin{aligned}
& \rho \frac{\mathrm{Du}}{\mathrm{Dt}}=\frac{\partial\left(-\mathrm{p}+\tau_{\mathrm{xx}}\right)}{\partial \mathrm{x}}+\frac{\partial \tau_{\mathrm{yx}}}{\partial \mathrm{y}}+\frac{\partial \tau_{\mathrm{zx}}}{\partial \mathrm{z}}+\mathrm{S}_{\mathrm{Mx}} \\
& \rho \frac{\mathrm{Dv}}{\mathrm{Dt}}=\frac{\partial \tau_{\mathrm{xy}}}{\partial \mathrm{x}}+\frac{\partial\left(-\mathrm{p}+\tau_{\mathrm{yy}}\right)}{\partial \mathrm{y}}+\frac{\partial \tau_{\mathrm{zy}}}{\partial \mathrm{z}}+\mathrm{S}_{\mathrm{My}} \\
& \rho \frac{\mathrm{Dw}}{\mathrm{Dt}}=\frac{\partial \tau_{\mathrm{xz}}}{\partial \mathrm{x}}+\frac{\partial \tau_{\mathrm{yz}}}{\partial \mathrm{y}}+\frac{\partial\left(-\mathrm{p}+\tau_{\mathrm{zz}}\right)}{\partial \mathrm{z}}+\mathrm{S}_{\mathrm{Mz}}
\end{aligned}
$$

In these equations, $\mathrm{S}_{\mathrm{M}}$ terms represent the momentum exchange between the oil droplets and the gas phase in each coordinate direction. Turbulence in the gas phase is modeled using Reynold stress model as suggested by many researchers in the literature [7].

\section{$\underline{\text { Reynold stress equation }}$}

Reynolds stress equation can be written as [4]

$$
\frac{\mathrm{DR}_{\mathrm{ij}}}{\mathrm{Dt}}=\frac{\partial \mathrm{R}_{\mathrm{ij}}}{\partial \mathrm{t}}+\mathrm{C}_{\mathrm{ij}}=\mathrm{P}_{\mathrm{ij}}+\mathrm{D}_{\mathrm{ij}}-\epsilon_{\mathrm{ij}}+\Pi_{\mathrm{ij}}+\Omega_{\mathrm{ij}}
$$

where, $C_{i j}$ represents rate of convection, $P_{i j}$ is rate of production, $D_{i j}$ is transport by diffusion, $\epsilon_{\mathrm{ij}}$ is rate of dissipation, $\Pi_{\mathrm{ij}}$ is transport due to turbulent pressurestrain interactions, $\Omega_{\mathrm{ij}}$ is transport due to rotation.

\section{Equation of motion of oil droplets}

Considering the forces acting on oil droplets, applying the Newton's second law to each droplet the following equation of motion is obtained for the droplets:

$$
\frac{d \vec{V}_{p}}{d t}=\frac{1}{\tau}\left(\vec{V}-\vec{V}_{d}\right)+\vec{g}\left(1-\frac{\rho_{g}}{\rho_{d}}\right)
$$

In this equation, $\vec{V}$ represents the velocity vector of continuous phase, $\mathrm{V}_{\mathrm{d}}$ is the velocity of droplets, $\rho_{d}$ density of droplets, and $\tau$ is characteristic time which $\tau$ can be shown as

$$
\tau=\frac{\rho_{g} d_{d}^{2}}{18 \mu f}
$$

In this equation dimensionless parameter, $f$ can be written as

$$
f=\frac{R e_{d} C_{d}}{24}
$$


In this equation, $C_{d}$ represents the drag coefficient between droplets and the gas phase.

Drag coefficient is calculated using correlations in the literature. In this study, Ishii Zuber method has been used. The advantage of Ishii Zuber method is using collision due to density differences of each phase [4]. Thus, this model can also work efficiently in case of high volume fraction. Droplet diameter in oil-gas mixtures may vary from $0.5 \mu \mathrm{m}$ to $200 \mu \mathrm{m}$ [8]. In this study, for the analysis of motion of droplets, the average droplet diameter was assumed to be $10 \mu \mathrm{m}$.

\section{Boundary conditions}

Geometry of flow domain and the coordinate system used are shown in fig. 2. As seen in this figure, oil-gas mixture enters the separator through the inlet. The oil separated from the mixture, is accumulated at the bottom and then it leaves the flow domain through the liquid exit at the bottom. The gas and the remaining oil mist in the gas leaves the separator through the exit at the top. In order to simulate the motion of both gas and oil droplets in the separator, the conditions at the inlet and outlets should be specified. At the inlet, the flow rate of each phase, volume fraction of each phase should be prescribed. At the exits, pressure is specified.

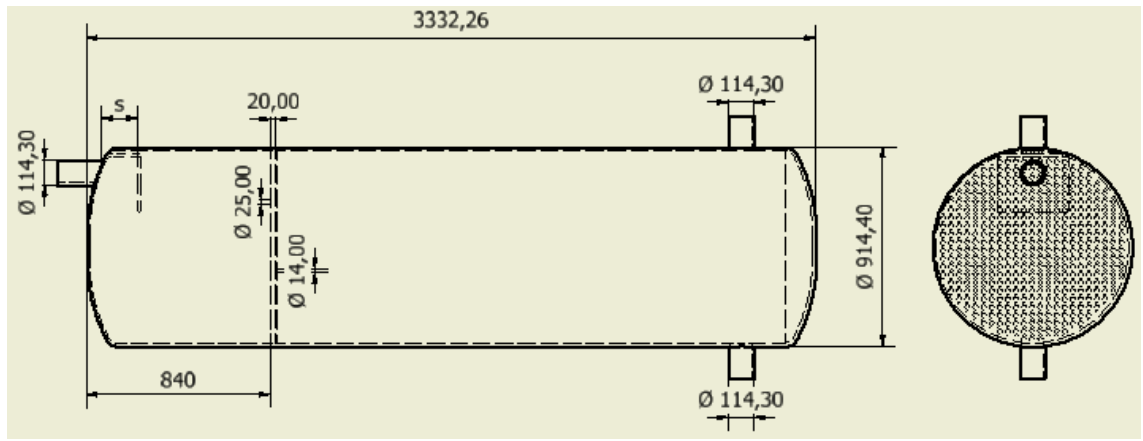

Figure 2: $\quad$ Problem geometry (Dimensions are in $\mathrm{mm}$ ).

\section{Numerical solution}

For the simulation of the flow field and then determination of separation efficiency, Eqs. (1) through (6) should be solved simultaneously together with the prescribed boundary conditions. The solutions are obtained using CFD software ANSYS CFX.

\section{Results and discussions}

The objective of this study is to investigate the effects of diverter location and presence of a perforated plate on the motion of the phases and on the separation 
efficiency. Hence, for all the simulations performed the inlet conditions, diameter and length of the separator were kept the same. The simulations were performed for different diverter locations with and without perforated plates in the separator.

For the oil-gas mixture given in Table 1, physical properties can be calculated by using the empirical equations from the literature [5].

Table 2: Physical properties of the oil-gas mixture considered in the simulations.

\begin{tabular}{|l|c|}
\hline Gas flow rate & $23.8 \mathrm{MMSCFD}$ \\
\hline Oil flow rate & $2000 \mathrm{BOPD}$ \\
\hline Oil volume fraction & 0.042 \\
\hline Gas volume fraction & 0.958 \\
\hline Operating pressure & $1000 \mathrm{psig}$ \\
\hline Surface tension & $13,68 \mathrm{din} / \mathrm{cm}$ \\
\hline Gas density & $3,801 \mathrm{lb} / \mathrm{ft}^{3}$ \\
\hline Oil density & $51,5 \mathrm{lb} / \mathrm{ft}^{3}$ \\
\hline Gas viscosity & $0,01269 \mathrm{cp}$ \\
\hline Oil viscosity & $2,37 \mathrm{cp}$ \\
\hline
\end{tabular}

The simulations were carried out for two different diverter plate distance from the inlet. The diverter plate was located at $\mathrm{s}=100 \mathrm{~mm}$ and $\mathrm{s}=170 \mathrm{~mm}$ from the inlet. In addition to these, simulations were also performed with perforated baffle plates when the diverter plate was positioned $170 \mathrm{~mm}$ from the inlet. The perforated plate is made by two different plates. One of these plates has holes with $12 \mathrm{~mm}$ diameter, and the other plate has holes with $25 \mathrm{~mm}$ diameter. Axes of holes on these two plates are eccentric with respect to each other by $18.5 \mathrm{~mm}$. The first perforated plate was placed $840 \mathrm{~mm}$ from the cap head and the second one was placed $860 \mathrm{~mm}$ from the cap head. To estimate the effects of these different configurations on separation efficiency, the CFD simulations results were compared.

The velocity vector fields for gas phase with diverter plate at $\mathrm{s}=100$ and $\mathrm{s}=$ $170 \mathrm{~mm}$ are given in fig. $3 \mathrm{a}$ and $3 \mathrm{~b}$, respectively. As seen in these figures, the gas issuing from the inlet with a high velocity impinges on the diverter plate. After the impingement, the velocity decreases and flow direction changes and the most of the fluid is diverted downward in the separator. Then the gas flows toward the exit with a lower velocity. This low velocity is required to give enough retention time for the oil droplets and allow the settlement of the oil mist. 


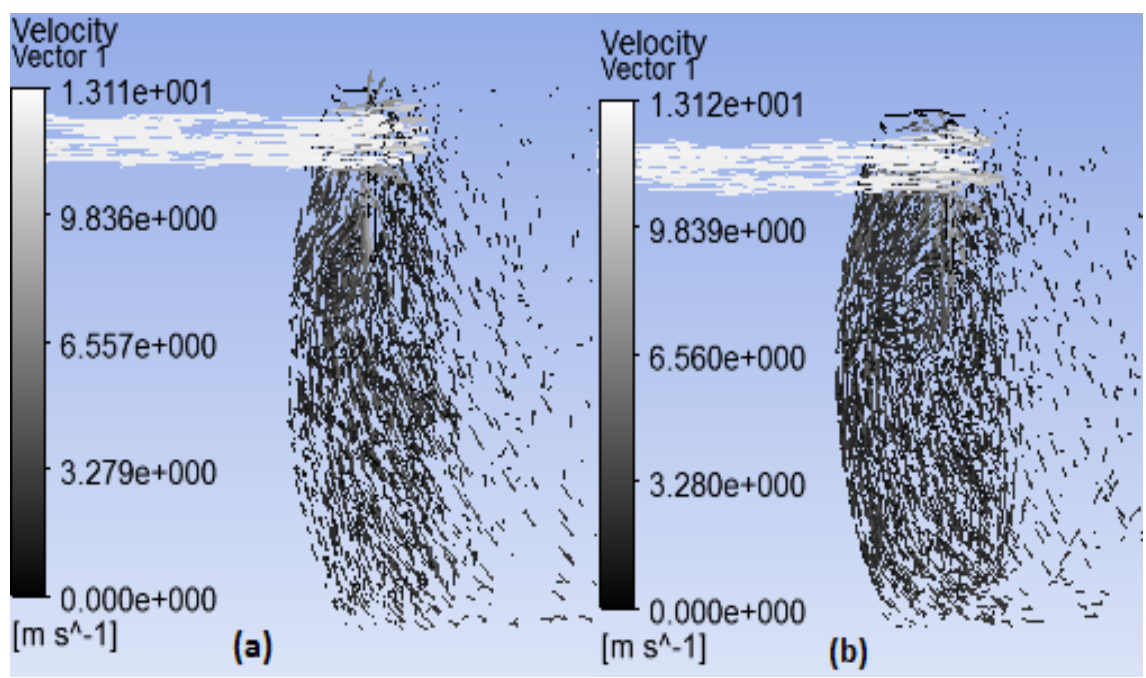

Figure 3: Velocity vector field of gas phase for two different diverter plate locations. (a) $\mathrm{s}=100 \mathrm{~mm}$, (b) $\mathrm{s}=170 \mathrm{~mm}$.

In fig. 4, the average droplet velocity distribution in the separator is given for the case with the diverter plate located at $\mathrm{s}=100 \mathrm{~mm}$. As seen in the figure, oil droplets have high velocities at the inlet. When they hit the diverter plate, the velocity of droplets decreases and droplets exchange their momentum to a considerable extend, as a results due to the gravity most droplets settle down to the bottom of the separator. Therefore, the separation of oil and gas takes place. The settling and separation of the oil droplets are clearly seen in fig. 5 which shows the droplet volume fraction contours.

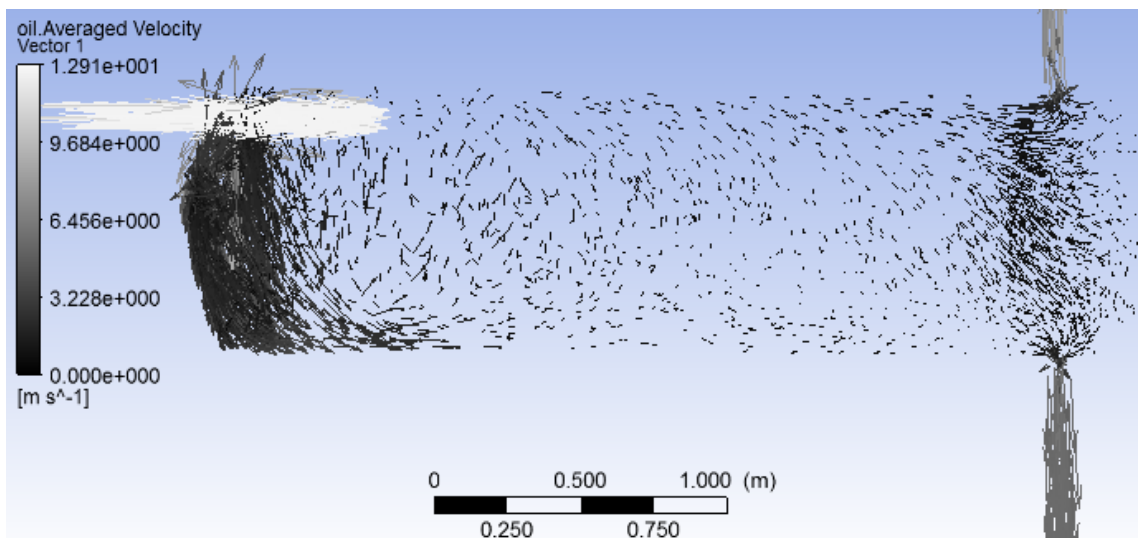

Figure 4: The average velocity vector field of oil droplets with diverter plate located at $\mathrm{s}=100 \mathrm{~mm}$. 


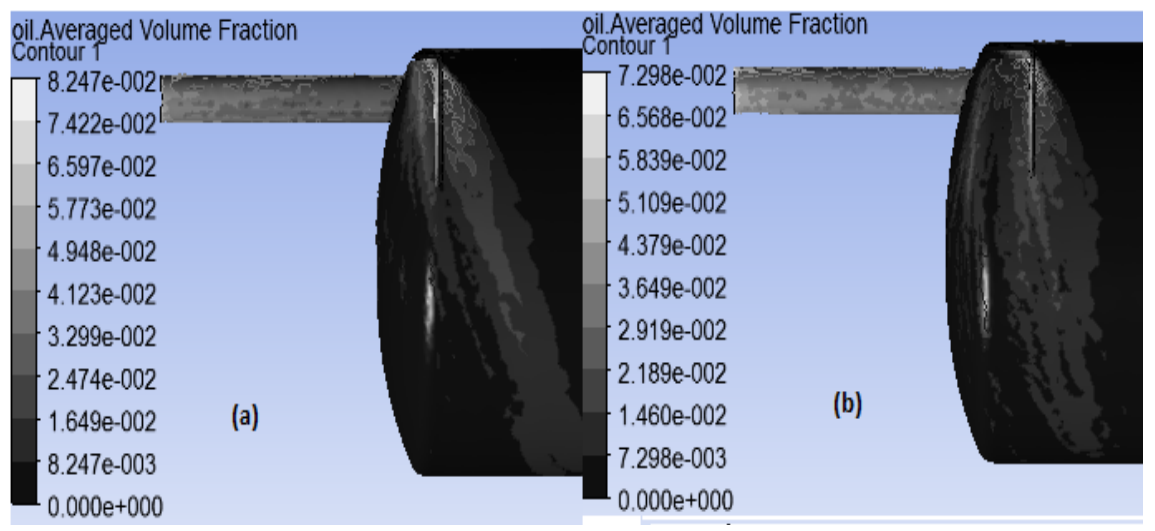

Figure 5: Oil averaged volume fraction for two different diverter plate locations. (a) $\mathrm{s}=100 \mathrm{~mm}$, (b) $\mathrm{s}=170 \mathrm{~mm}$.

Volume fraction contours in fig. 5 show that most of the oil droplets settle down in the region close to the inlet. However, a careful observation of the volume fraction distribution indicates that a small amount of the oil flows with gas phase toward the exit. To hold these oil droplets and separate them from the gas phase, two perforated plates are placed in the separator. Droplet average velocity vector field for the separator with perforated plate is given in fig. 6. As seen in this figure, as there is a high droplet velocity before the perforated plate, it decreases after the perforated plate. This indicates that, perforated plate play a positive role on the separation of the oil droplets.

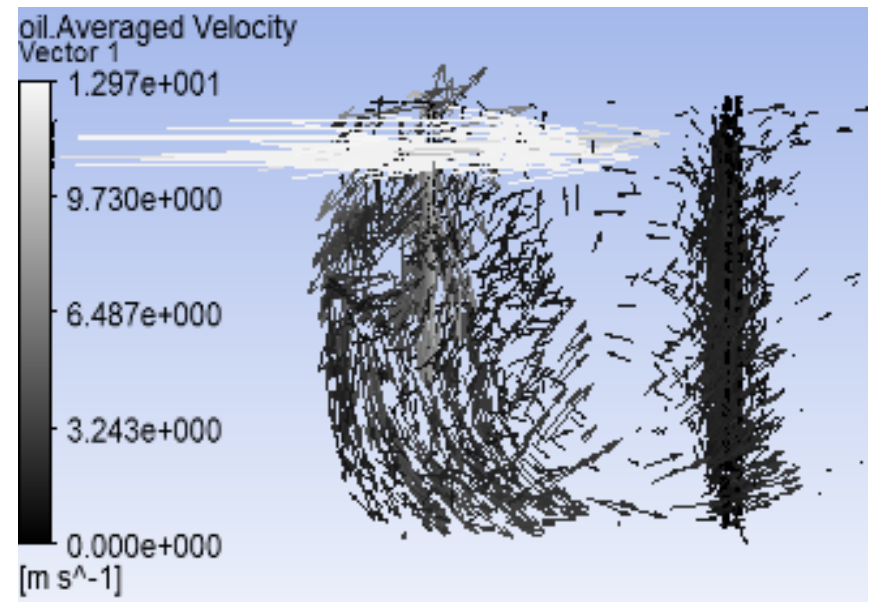

Figure 6: Oil average velocity vector field in the separator with diverter plate located at $\mathrm{s}=170 \mathrm{~mm}$ and perforated plates. 


\section{$\underline{\text { Separation efficiency }}$}

To estimate the effects of the diverter plate position and perforated plates on the separation process, the separation efficiency was calculated as follows and compared with each other.

$$
\eta=100 \frac{\dot{m}_{o] \text { inlet }}-\dot{m}_{\text {o]gas outlet }}}{\dot{m}_{\text {o]inlet }}}
$$

Separation efficiencies for three cases considered are given in Table 3 together with inlet and outlet oil mass flow rates. As seen in this table, with increasing diverter plate distance from the inlet, the separation efficiency increases. The perforated plate also plays a positive role on the separation efficiency. Despite of the increase in the efficiency is small, small efficiency increases may be very important for an oil production site because a small efficiency increase may result a considerable profit for a continuously running plant. A petroleum company, which produces about 25,550,000 barrels of oil per year, can save 252,945 barrels of oil every year if the separation efficiency increases by $0.99 \%$. This provides $27,823,950 \$$ extra profit per year.

Table 3: Separation efficiency for the cases studied.

\begin{tabular}{|l|c|c|c|c|c|l|l|}
\hline Case & $\dot{m}_{o} / \dot{m}_{g}$ & $\begin{array}{c}\dot{m}_{\text {o]inlet }} \\
{[\mathrm{kg} / \mathrm{s}]}\end{array}$ & $\begin{array}{l}\dot{m}_{\text {o]gas outlet }} \\
{[\mathrm{kg} / \mathrm{s}]}\end{array}$ & $\begin{array}{l}\dot{m}_{\text {o]oil outlet }} \\
{[\mathrm{kg} / \mathrm{s}]}\end{array}$ & $\begin{array}{l}\text { Diverter location, s } \\
(\mathrm{mm})\end{array}$ & $\begin{array}{l}\text { Perforated } \\
\text { plate }\end{array}$ & $\eta(\%)$ \\
\hline 1 & 0.2594 & 3.30656 & 0.0495984 & 0.0394583 & 100 & No & 98.5 \\
\hline 2 & 0.2594 & 3.30656 & 0.0224846 & 0.0081562 & 170 & No & 99.32 \\
\hline 3 & 0.2594 & 3.30656 & 0.0169737 & 0.0249094 & 170 & Yes & 99.49 \\
\hline
\end{tabular}

\section{Conclusion}

In this study, to analyze the effects of position of the diverter and perforated plates on the separation efficiency, two-phase flow simulations were conducted using CFD software ANSYS CFX. The CFD simulations were carried out for two different diverter plate distances from the inlet. Diverter plate was located at $100 \mathrm{~mm}$ and $170 \mathrm{~mm}$ from the inlet. In addition to these, simulation was also performed with perforated baffle plates when the diverter plate is positioned 170 $\mathrm{mm}$ from the inlet. To estimate the effects of these different configurations on separation efficiency, the CFD simulations results were compared.

It has been observed that perforated plates and position of the inlet diverter affect the separation efficiency. When the inlet diverter is located at $100 \mathrm{~mm}$ from the inlet, the separation efficiency of $98.5 \%$ is obtained. When the inlet diverter is located at a distance of $170 \mathrm{~mm}$ from the inlet, the separation efficiency increases to $99.32 \%$. When perforated plates are assembled to the separator, the separation efficiency increases further. Finally, this study has demonstrated that the internal design of oil-gas separators is important, because even a very small increase in separation efficiency may save a lot of money. 
This research is still under development, it is planned to present a benchmark between the field information and the CFD simulations, in order to perform a sensitivity analysis and evaluate the dependence of the main properties, models, interpolation schemes, mesh, analysis type and its results.

\section{Abbreviations}

BOPD: Barrels per day

MMSCFD: Million standard cubic feet per day

\section{References}

[1] Guo, B., Lyons, W.C., Ghalambor, A., Petroleum Production Engineering (Chapter 10). Topics in Separation Systems, Elsevier Science \& Technology Books, pp. 118, 2007.

[2] Arnold, K., Stewart, M., Gas-Liquid and Liquid-Liquid Separators, British Library Cataloguing-in-Publication Data, USA, pp. 69-73, 2008.

[3] Abdulkadir, M., Perez, V., Sharaf, S., Lowndes, I.S., Azzopardi, B., Experimental Investigation of Phase Distributions of Two-phase Air-silicone Oil Flow in a Vertical Pipe, World Academy of Science, Engineering and Technology, 61, 2010.

[4] Méndez, J., Evaluation of Vertical Tanks Gas-Liquid Separation by Gravity, Master Thesis, Del Zulia University, Venezuela, pp. 43-44, 2012.

[5] Brill, J.P., Mukherjee, H., Multiphase Flow in Wells, Society of Petroleum Engineers Inc., Texas, pp. 18-21, 103-120, 1999.

[6] Karabey, A., Numerical Analysis of Gas-Solid Particule Two Phase Flow for Size Classification of Particules, Ph.D. Thesis, Gazi University, Turkey, 2001.

[7] Versteeg, H., Malalasekera, W., An Introduction to Computational Fluid Dynamic (Chapter 3). Topics in Turbulence and its Modeling, Longman Scientific, England, pp. 75-78, 1995.

[8] Arnold, K., Stewart, M., Emulsions and Oil Treating Equipment Selecting, Sizing and Troubleshooting, British Library Cataloguing-in-Publication Data, USA, pp. 116, 2009. 